\title{
Total Quality Management and Customer Loyalty: A Survey of the Quality Management
}

\author{
Thi Le Ha Nguyen \\ University of Medicine and Pharmacy, Vietnam National University, Hanoi, Vietnam
}

Email address:

ng.leha72@yahoo.com

To cite this article:

Thi Le Ha Nguyen. Total Quality Management and Customer Loyalty: A Survey of the Quality Management. American Journal of Management Science and Engineering. Vol. 6, No. 3, 2021, pp. 56-62. doi: 10.11648/j.ajmse.20210603.11

Received: June 16, 2021; Accepted: July 5, 2021; Published: July 13, 2021

\begin{abstract}
Objective: Total quality management (TQM) is a useful tool for improving the perceived service quality to increase the customers' satisfaction (CS) and to maintain their loyalty. The purpose of this study examines TQM in relation to CS and loyalty. Method: A self-administered questionnaire was administered to the inpatients who were treated at the National Cancer Hospital, in Vietnam, in April 2018. A total of 516 documents used the analyzed procedure. The dataset was analyzed via the SPSS software 25.0, and the Amos 25.0. A confirmatory factor analysis was performed to test the structural equation modeling of the proposed hypotheses. Results: TQM directly influences CS and has a positive influence on loyalty. Our findings revealed that TQM is the key factor that directly influences CS and loyalty; CS performs a mediating role in the relationship between TQM and loyalty. Implications: The findings have implications for managers and policymakers that TQM factors include Process, Interaction, and Environment quality should be considered in planning with an aim to increase CS and to maintain their loyalty. Therefore, it increases profits for providers that contribute to sustainable survival in a competitive environment. Besides, satisfaction is a mediator factor of TQM and loyalty, so the service organization should consider customers' satisfaction to maintain loyalty.
\end{abstract}

Keywords: Total Quality Management, Satisfaction, Loyalty

\section{Introduction}

Total quality management (TQM) is considered a standard system of management that focused on customer [1]. The concept of TQM began between 1970 and 1993 under different names. These include: inspection quality control (IQC), statistical process control (SPC), total quality control (TQC), and company-wide quality control (CWQC). Finally, it established as TQM in the 1980s [2, 3]. TQM focuses on the product quality, the production process quality, the service quality, the service's process quality, business planning, strategic quality planning, and the integrated strategic quality planning $[1,4,5]$. The service quality's aspects include the tangibility, reliability, responsiveness, assurance, and empathy [6]. These aspects of service focus on client satisfaction with products and services [4]. Service organizations have developed their service quality to increase the customers' satisfaction and loyalty [6]. Researchers supported five key factors including process quality, interaction quality, environmental quality, cost, and overall satisfaction [7].

In Vietnam, most public hospitals are not enough medical equipment and outdated facilities. Consequently, their processes, interactions, and environmental quality don't get professional standards. These public hospitals have distributed free patient healthcare for those who hold health insurance cards. This is except for diagnosis and treatments that require specialized technology. Moreover, hospitals have an excess of patients who use healthcare services. Therefore, hospitals that give diagnostic and treatment practices are unsafe. The author selected three factors: process, interaction, and environmental quality. A sample size of about 500 participants is suitable for factor loading of the proposed model.

Service quality is a core factor in the service industry's competitive environment [8]. Therefore, measuring the customers' satisfaction is used to evaluate and assess the service organizations' service quality [1]. The perceived quality of the service's various aspects was used to assess the customers' satisfaction and loyalty $[9,10]$. When consumers 
have high satisfaction levels, they predict their willingness to repurchase [11]. The perceived quality directly influences the clients' satisfaction and indirectly affects the customers' loyalty through the mediating role of satisfaction [9].

In the healthcare industry, patient satisfaction (PS) is a useful metric to measure the service quality of providers [12]. The gap between the expectation and perceived service quality was measured by the customer for the service firm's service quality [12]. The perceived quality of the service is related to satisfaction and loyalty [9]. The customers' satisfaction lead to positive word-of-mouth communication [13].

The customers' loyalty is a core factor for consideration when assessing a provider's service quality. This is due to the perceived quality having a positive influence on the users' satisfaction and loyalty [9]. The customers' satisfaction with the service quality predicts the service organization's repurchase [11]. It is a mediator factor of the perceived quality and loyalty [9]. Therefore, the organization increase the service quality to attract and maintain customer [8, 14].

\section{Literature Review}

This study examines a model that focuses on three factors: TQM, PS, and patient loyalty (PL).

\subsection{TQM}

TQM is a leadership tool that allows the service organizations to increase their competitive strategies [4]. It is a continually improving process that aims to fulfill the customers' service quality [5]. TQM focuses on client satisfaction which is an essential aspect of the quality system. they are key to improving the service quality [1]. The measuring and assessing of the customers' satisfaction in various parts of a service is a crucial step in evaluating the perceived quality and the consumers' expectations [12].

The service quality's core aspects include tangibility, reliability, responsiveness, assurance, and empathy. The tangibility focuses on facilities, equipment, personnel, and communication channels. Reliability represents the ability of service that safe and dependable. The responsiveness considers the willingness to cooperate of staff with clients. Empathy focuses on an approach to the client that based on their mood. The assurance concerned about a firm's ability to show confidence in their customers about competence provided [15]. Previous research demonstrates that four service quality factors include process quality, interaction quality, environmental quality, and cost are key to consumer satisfaction and customers' loyalty to service firms [7].

\subsection{PS}

Service quality is a key element in a sustainable competitive advantage [8]. Therefore, the customers' satisfaction measures the parts of the service that are useful tools for improving the service companies' service quality [6]. The service providers fulfill customer expectations, and perceived service quality can increase consumer satisfaction and willingness to repurchase [11]. Thus, the service firm considers increasing the service quality and fulfills the customers' expectations to improve their satisfaction and loyalty [16]. The customers' satisfaction plays a mediating role in both the perceived quality and expectations related to their loyalty [16]. The PS is the patient's expected outcome in the health service organization. This is an indispensable factor for the provider's service quality [17].

\subsection{The PL}

In the service industry, the customers' satisfaction and loyalty are regarded as key factors in business strategies [18]. The service quality and trust are predictors of job satisfaction [14]. Therefore, customers satisfaction is a tool to measure and evaluate the service quality. This is where customers compare the perceived quality with their expectations [6]. The service providers have attracted and retained customers by meeting the customers' expectations regarding the service quality that contribute to their loyalty [16]. The perceived quality influences client's satisfaction and loyalty [9]. Customers' satisfaction plays a mediating role between the perceived quality and their expectations related to their loyalty [16]. Improving the perceived value is anticipated to increase the customers' satisfaction and their continuance intention [19].

\subsection{The Research Hypotheses}

The customers' satisfaction is a useful measurement of the service quality for providers [17]. The perceived quality and the expectations are predictive factors of the consumers' satisfaction [16]. The quality processes that include the processes, interactions, the environmental quality, and the cost affect the overall satisfaction [7]. The perceived service quality has a positive influence on customer satisfaction [6]. This includes the tangible objects, reliability, responsiveness, assurance, and empathy. There is a gap of the perceived service quality and the expectations in the assessed service quality [12]. Consumer satisfaction is mediator factor of the perceived quality and loyalty [9]. Therefore, the hypothesis is:

H1: TQM has a positive relation to the PS.

$\mathrm{Ma}$ et al. [20] indicated that service quality has a significant influence on customer loyalty. The aspects of the perceived quality, including the tangible objects, reliability, responsiveness, and empathy, had a positive effect on the potential PL [21]. In addition, switching costs are associated with high switching costs related to their customers' loyalty [22]. The perceived quality directly influences customers' loyalty, or plays a mediating role indirectly via satisfaction [9]. Based on these discussions, the hypothesis gave:

H2: TQM influences the PL.

The perceived service quality and expectations are the main factors related to the customers' satisfaction and loyalty [16]. The service quality was improved to meet the customers' expectations to maintain the users' satisfaction [12]. The perceived quality is directly related to the consumers' 
satisfaction and loyalty, or indirectly through satisfaction, that plays a mediating role [9]. Thus, the hypothesis proposed:

H3: The PS influences the PL.

\section{Materials and Methods}

The members recruited were trained for one day for the study's purpose. They assisted in collecting the data. A sample size of 500 participants was required for structural equation modeling (SEM) based on Wolf et al. [23]. The participants who participated in the survey signed the participant information sheets and consent forms.

The respondents were randomly selected from $22 \%$ of the total 2,500 inpatients among 39 departments that treated cancer specialist medical fields in the National Cancer Hospital, Vietnam. A total of 550 participants required for this study. The participants who did not complete the questionnaires were included.

A self-administered questionnaire was dispensed, including 24 questions in two main parts. In the first part, the socio-demographic factors consisted of six questions. In the second part, 18 questions related to the three factors of TQM, the PS, and the PL. The TQM factor includes 12 questions related to the process quality (TQM1-TQM4). Five questions refer to the interaction quality (TQM5-TQM9), and three questions are on the environmental quality (TQM10TQM12). The questions' content are based on a prior study by Zarei et al. [24, 25]. The author modified the questions to fit into the research hospitals' contexts. Following this, the PS factor was concerned with three questions (PS13-PS15). Finally, there are three questions regarding the PL factor (PL16-PL18). All the study's questions were assessed using a Likert scale classifies from one to five.

The dataset was performed by using SPSS version 25.0 software for descriptive statistics of the socio-demographic characteristics of participants. Confirmatory factor analysis (CFA) was performed to support the issues of the model's dimensionality and convergent and discriminant validity. SEM was used to test the proposed hypotheses using Analysis of Moment Structures (AMOS) 25.0.

\section{Results and Discussion}

\subsection{The Reliability Statistics}

Our study applied Cronbach's Alpha to support the consistency of each item under the same construct using SPSS version 25.0. The Likert scale assessing the items of this study range from "very strongly disagree" (1) to "very strongly agree" (5). The results indicated in Table 1.

Table 1 reveals the factors' composed reliability. In particular, the TQM factor was approximately 0.82 to 0.90 . The PS factor was 0.79 . The PL factor was 0.80 . We note that all constructs are over 0.70 . This established that the scales were acceptable. Moreover, one item was rejected to ensure the scales' reliability.

Table 1. Reliability statistics.

\begin{tabular}{lll}
\hline Constructs & Items & Cronbach's Alpha \\
\hline Total Quality Management & & \\
Process quality & 4 & 0.896 \\
Interaction quality & 5 & 0.890 \\
Environment quality & 3 & 0.823 \\
Patients' Satisfaction & 3 & 0.792 \\
Patients' Loyalty & 2 & 0.800 \\
\hline
\end{tabular}

This table shows the alpha coefficients that exceeded the reliability threshold of 0.70 , confirming the reliability and adequate internal consistency of the scales

\section{2. $C F A$}

The CFA was assessed the SEM's fit [26]. Our model was measured via the standardized coefficients, composite reliabilities (CR), and the average variance extracted (AVE) [26], as illustrated in Table 2.

Table 2 showed that the standardized coefficients of items were around 0.67 to 0.86 [cut-off $=0.5$ ]. The AVE values ranged from $0.57-0.67$ [cut-off $=0.5$ ]. The $\mathrm{CR}$ values for all constructs were from 0.80 and 0.94 [cut-off $=0.7$ ]. The AVEs were over the squared correlations between any pair of constructs, implying high discriminant validity [26]. The results indicate that the model was supported.

Table 2. Confirmatory factor analysis results and model goodness-of-fit.

\begin{tabular}{llll}
\hline Construct measures & Standardized coefficients & Average variance extracted (AVE) & Composite reliability (CR) \\
\hline Total Quality Management (TQM) & & 0.586 & 0.944 \\
TQM1 <---TQM & 0.835 & & \\
TQM2 <---TQM & 0.745 & & \\
TQM3 <---TQM & 0.797 & \\
TQM4 <---TQM & 0.839 & \\
TQM5 <---TQM & 0.831 & \\
TQM6 <---TQM & 0.797 & & \\
TQM7 <---TQM & 0.775 & & \\
TQM8 <---TQM & 0.780 & & \\
TQM9 <---TQM & 0.675 & & \\
TQM10 <---TQM & 0.727 & \\
\hline
\end{tabular}




\begin{tabular}{|c|c|c|c|}
\hline Construct measures & Standardized coefficients & Average variance extracted (AVE) & Composite reliability (CR) \\
\hline TQM11<---TQM & 0.674 & & \\
\hline TQM12<---TQM & 0.682 & & \\
\hline Patient Satisfaction (PS) & & 0.570 & 0.798 \\
\hline PS13<---PS & 0.782 & & \\
\hline PS14<---PS & 0.796 & & \\
\hline PS15 <---PS & 0.682 & & \\
\hline Patient Loyalty (PL) & & 0.671 & 0.803 \\
\hline PL16 <---PL & 0.862 & & \\
\hline PL17 <---PL & 0.774 & & \\
\hline
\end{tabular}

Chi-square $(\mathrm{CMIN} / \mathrm{DF})=2.930 ; \mathrm{CMIN}=322.288 ; \mathrm{DF}=110 ; \mathrm{P}=0.000$

$\mathrm{GFI}=0.929 ; \mathrm{AGFI}=0.902 ; \mathrm{CFI}=0.963 ; \mathrm{TLI}=0.955 ; \mathrm{NFI}=0.946 ; \mathrm{RMSEA}=0.061$

The standardized coefficients were required to exceed a threshold of 0.5 . The CR values thus met the cut-off value of 0.70 for adequate internal consistency. The AVE values were evaluated in terms of the cut-off of 0.50 .

\subsection{The Model Goodness-of-Fit}

The fit of the research model was supported by the absolute, incremental, and parsimony fit measures. It was also assessed by the basic elements underlying all the basis of the goodness-of-fit measures, as indicated in Table 2.

As shown in Table 2, the ratio of $\chi^{2}$ to the degrees of freedom was $2.930(\mathrm{P}=0.000)$. The fit indices included [GFI] $=0.929$ [cut-off $=0.80$ ]; the normalized fit index $[\mathrm{NFI}]=$ 0.946 [requirement $=$ value of $0-1$ ] and the root mean squared error of approximation [RMSEA] $=0.061$ [requirement $=$ value from $0.05-0.08$ ]. It also included the comparative fit index $(\mathrm{CFI})=0.963$; the adjusted goodness of fit index $[\mathrm{AGFI}]=0.902$ [cut-off $=0.80]$; and the TuckerLewis index [TLI] $=0.955$ [cut-off $=0.9]$ [26]. The model's reliability and validity requirements were acceptable.

\subsection{Hypotheses Testing}

The study's hypotheses are presented in Table 3, which shows that the path coefficient with the standardized coefficients are statistically significant (the requirement significance is less than 0.05), indicating that they are the influence factors. The standardized coefficients show the direction of the impact.

Table 3. The hypothesis test results.

\begin{tabular}{lllll}
\hline Hypothesis & Path & Standardized coefficients & Sig. & Results \\
\hline H1 & TQM--->PS & 0.717 & $* * *$ & Accepted \\
H2 & TQM--->PL & 0.302 & $* * *$ & Accepted \\
H3 & PS--->PL & 0.358 & $* * *$ & Accepted \\
\hline
\end{tabular}

The hypotheses were evaluated by standardized coefficients and path coefficients, with a significance (sig.) of less than 0.05 . The symbol *** represents (sig. $=0.001)$. The acronyms are total quality management (TQM), patient satisfaction (PS), and patient loyalty (PL).

Hypothesis H1: The TQM related to the PS was supported by the path's (TQM---> PS) coefficient at a statistical significance of $0.717(p=0.001)$. This showed that the TQM influences the PS, similar to previous research [16]. The service quality measured in terms of the service quality based on the customers' perceived quality [6]. Thus, providers increase the customers' satisfaction and loyalty by improving their perceived quality (Huang et al. 2019). Moreover, there was a gap in the relationship between the perceived quality and their expectations [6]. This suggests that there is a close relationship between service quality and expectations that impact their satisfaction and loyalty [16]. The perceived quality is directly related to their satisfaction and loyalty [9]. It can also be indirectly related to their loyalty through their satisfaction that plays a mediating role [10].

Hypothesis H2: The TQM had a significant influence on the PL that was presented by the path's co-efficient $(\mathrm{TQM} \rightarrow \mathrm{PL})$. This occurred at a statistical significance of $0.302(p=0.001)$. This is similar to Lin et al.'s (2004) results. Ma et al. [20 showed that aspects of the perceived quality are related to customers' loyalty [20]. Moreover, the perceived quality has a close relationship with the expectation that their loyalty via satisfaction is indirectly a mediating factor [16]. The perceived quality can also directly or indirectly affect the customers' loyalty [9].

Hypothesis H3: The PS has a positive influence on the $\mathrm{PL}$, as indicated by the coefficient of the path directly (PS--->PL), with a statistical significance of $0.358(\mathrm{p}=$ 0.001). Similarly, the customers' satisfaction influences directly their loyalty [18]. Their satisfaction is a mediator factor between the service quality and repurchase [10]. Moreover, consumer satisfaction is a mediator of expectations and loyalty [16].

\subsection{Implications for Practice}

Our study has implications for service organizations and policymakers when considering TQM. This includes the processes, interactions, and the environmental quality, as the key factors directly related to the customers' satisfaction and loyalty. Moreover, the findings contribute to the policymakers' contributions when developing a strategic plan to improve the customers' satisfaction and to increase their loyalty. 


\section{Conclusion and Recommendations}

Our study has implications for service organizations and policymakers, as it examines the influence of TQM on the PS and PL. The study was conducted at the highest-level hospital, Vietnam in April 2018. It was conducted using a self-administered questionnaire with 516 documents that used the analyzed procedure. CFA was used for SEM to test the proposed hypotheses.

Our findings showed that TQM was directly related to the PS, PL, and the PS on the PL. This reveals that TQM is a core factor in planning to attract customers to increase their satisfaction and retain their loyalty. Therefore, increasing profits for service companies contribute to sustainable survival in a competitive environment. In addition, satisfaction is a mediating role in TQM and loyalty.
Therefore, the providers should focus on their customers' satisfaction to maintain loyalty. Moreover, the study develops our knowledge of how the various aspects related to the service quality affect the users' satisfaction and loyalty.

\section{Declaration of Interest Statement}

The authors declare that they have no competing interests.

\section{Acknowledgements}

The author would like to thank the research team of the National Cancer Hospital in Hanoi, Vietnam, and the inpatients who responded to this study. No funding for this work.

\section{Appendix}

\section{QUESTIONNAIRE}

The Total Quality Management and Customer Loyalty: A Survey of Quality Management

Your responses will be used solely for research purposes. The information that you provide will help improve the quality of healthcare services.

Serial No:

Date of completion.

Please write your response in the blank column or mark the box provided.

1. What is your age? years

2. What is your sex?

1. Male

3. What is your marital status?

1. Single

3. Divorced

4. What is your educational level?

1. No schooling

3. Secondary school

5. Bachelor's degree

5 . What is your occupation?

1. Govt. employee

3. Unemployed

5. General labor

6. Method of paying your hospital fees

1. Insurance

Please place a cross in the box corresponding to the level of your agreement/disagreement with each of the following statements:

1. Very strongly disagree, 2. Strongly disagree, 3. Agree, 4. Strongly agree, 5. Very strongly agree

Total Quality Management (TQM)

Statement/Item

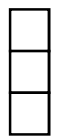

2. Primary school

4. High school

6. Postgraduate degree

2. Non-govt. employee

4. Agriculture

6. Retired

2. Personal payment
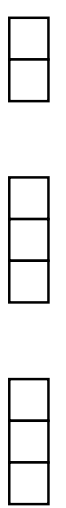

Process quality

TQM1 Services were provided on time.

TQM2 I was informed as to when services would be performed.

TQM3 Staff were available when needed. 
TQM4 Medical and non-medical services were provided promptly.

Interaction quality

TQM5 Round-the-clock services were available.

TQM6 Staff were polite and friendly.

TQM7 Staff had my best interests at heart.

TQM8 Staff understood my specific needs.

TQM9 Staff were knowledgeable when answering my questions.

Environment quality

TQM10 The hospital environment was clean and comfortable.

TQM11 The employees were well dressed and neatly presented.

TQM12 The equipment was up-to-date.

Patient Satisfaction (PS)

Statement/Item

PS13 I am satisfied with my recovery's results.

PS14 The service quality I received met my expectations.

PS15 I am satisfied with my selection of this hospital to provide me with healthcare.

Patient Loyalty (PL)

Statement/Item

PL16 I would return to this hospital if I required healthcare in the future.

PL17 I would recommend this hospital to others.

PL18 I do not want to use other healthcare service providers.

\section{References}

[1] ISO 10001. International standard: Quality managementcustomer satisfaction- guidelines for codes of conduct for organizations. 1st ed. Geneva: ISO; 2007.

[2] Juran JM., Godfrey AB, Hoogstoel RE, et al. Juran's quality handbook. 5th ed. New York, NY: McGraw-Hill; 1998.

[3] Aized T. Total quality management and Six Sigma. Croatia: Janera Trdine: 2012.

[4] ISO 9000. International standard: Quality management systems-fundamentals and vocabulary. 4th ed. Geneva: ISO; 2015.

[5] ISO 9001. International standard: quality management systems- requirements. 5th ed. Geneva: ISO; 2015.

[6] Bashir A, Bastola DR. Perspective of nurses toward telehealth efficacy and quality of health care: Pilot study. JMIR Medical Informatics. 2018; 6 (2): 1-10.

[7] Arab MS, Tabatabaei MG, Rashidian A, et al. The effect of service quality on patient loyalty: A study of private hospitals in Tehran, Iran. Iranian Journal Public Health. 2012; 41 (9): 71-77.

[8] Purcarea TV. Creating the ideal patient experience. Journal of Medicine and Life. 2016; 9 (4): 380-385.

[9] Chen C, Tsai, M. Perceived value, satisfaction, and loyalty of TV travel product shopping: Involvement as a moderator. Tourism Management. 2008; 29: 1166-71.

[10] Lee Y, Wang Y, Lu S, et al. An empirical research on customer satisfaction study: A consideration of different levels of performance. Springer Plus. 2016; 5 (1577): 1-9.
[11] Schaal T, Schoenfelder T, Klewer J, et al. Determinants of patient satisfaction and their willingness to return after primary total hip replacement: a cross-sectional study. BMC Musculoskeletal Disorders. 2016; 17: 330: 1-9.

[12] Zun AB, Ibrahim MI, Hamid AA. Level of satisfaction on service quality dimensions based on SERVQUAL model among patients attending 1 Malaysia clinic in Kota Bharu, Malaysia. Oman Medical Journal. 2018; 33 (5): 416-422.

[13] Alrwashdeh M, Jahmani A, Ibrahim B, et al. Data to model the effects of perceived telecommunication service quality and value on the degree of user satisfaction and e-WOM among telecommunications users in North Cyprus. Data in Brief. 2020; 28: 1-10.

[14] Gider O, Akdere M, Top M. Organization trust, employee commitment and job satisfaction in Turkish hospitals: Implications for public policy and health. EMHJ. 2019; 25 (9): 622-629.

[15] Papanikolaou V, Zygiaris S. Service quality perceptions in primary health care centres in Greece. Health Expectations. 2012; 17: 197-207.

[16] Chen Y, Liu J, Xiao S, et al. Model construction of nursing service satisfaction in hospitalized tumor patients. International Journal Clinical Experimental Medicine. 2014; 7 (10): 3621-29.

[17] Firlej E, Janiszewska M, Sidor K, et al. Health evaluation in the context of satisfaction with medical service among patients with osteoarthritis: Descriptive cross-section survey. International Journal of Environmental Research and Public Health. 2020; 17 (9): 1-15.

[18] Huang C, $\mathrm{Wu} \mathrm{H}$, Lee $\mathrm{Y}$, et al. What role does patient gratitude play in the relationship between relationship quality and patient loyalty? The Journal of Health Care Organization, Provision, and Financing. 2019; 56: 1-8. 
[19] Masri NW, You J, Ruangkanjanases A, et al. Assessing the effects of information system quality and relationship quality on continuance intention in E-tourism. International Journal of Environmental Research and Public Health. 2020; 17 (174): 115 .

[20] Ma F, Guo D, Yuen KF, et al. The influence of continuos improvement of public car-sharing platforms on passenger loyalty: A mediation and moderation analysis. International Joural of Environmental Research and Public Health. 2020; 17 (2756): 1-21.

[21] Lin H, Xirasagar S, Laditka JN. Patient perceptions of service quality in group versus solo practice clinics. International Journal for Quality in Health Care. 2004; 16 (6): 437-445.

[22] Huifeng P, Ha H. Do customers pay attention to motivations and switching costs when they terminate their relationships? Frontiers in Psychology. 2020; 11 (798): 1-17.

[23] Wolf EJ, Harrington KM, Clark SL, et al. Sample size requirements for structural equation models: An evaluation of power, bias, and solution propriety. Educational and Psychological Measurement. 2023; 73 (6): 913-934.

[24] Zarei E, Daneshkohan A, Khabiri, et al. The effect of hospital service quality on patiet's trust. Iran Red Crescent Med Journal. 2015; 17 (1): 1-5.
[25] Zarei E, Daneshkohan A, Pouragha B, et al. An empirical study of the impact of service quality on patient satisfaction in private hospitals, Iran. Global Journal of Health Science. 2015; 7 (1): 1-9.

[26] Hair JF, Black B, Babin BJ, et al. 2014. Multivariate data analysis. 7th ed. London, UK: Prentice Hall; 2014.

\section{Biography}

Thi Le Ha Nguyen has been a medical doctor for 21 years in Vietnam. She works as an internal medicine doctor at the Department of Internal Medicine - Pediatrics - Infectious Diseases of the Traditional Medicine General Hospital, Hanoi, Vietnam. Currently, she is a lecturer at the Department of public health and preventive medicine, University of Medicine and Pharmacy, Vietnam National University, Hanoi. She studies in the healthcare management field. She graduated from Mahidol University, Thailand, and was awarded a Master's degree in primary healthcare management. She holds awarded a doctoral program in healthcare management from the Graduate School of Medical Sciences, Kanazawa University, Japan. 